\title{
Whom to Believe: Recruiting Information Source Credibility and Organizational Attractiveness
}

\author{
Troy V. Mumford \\ Department of Management, College of Business \\ Colorado State University, 222 Rockwell Hall \\ Fort Collins, CO 80523-1275, USA \\ E-mail: troy.mumford@colostate.edu
}

Received: October 13, 2012

Accepted: October 29, 2012

Online Published: October 31, 2012

doi:10.5430/bmr.v1n4p63

URL: http://dx.doi.org/10.5430/bmr.v1n4p63

\begin{abstract}
This study uses a policy-capturing methodology to investigate how job seekers faced with conflicting recruiting information make organizational attractiveness judgments. It proposes that when considering recruiting information, the credibility of the information source, in terms of trustworthiness, expertise, integrity, and liking, will be positively related to the extent to which information from each source is used when judging the attractiveness of organizations. The results indicated that some sources are seen as more credible than others, and that this credibility is related to the use of information from that source. In addition, the dimensions of credibility most highly related to information use are different for interpersonal and institutional sources. The implications for employee recruiting research and practice are discussed.
\end{abstract}

Keywords: Job Choice, Recruiting, Source, Credibility, Trust, Decision-making

\section{Introduction}

Global Organizations trying to attract the top talent face job seekers who gather information about the organization from multiple sources. How do job seekers make sense of conflicting information? How should recruiters use different information sources to communicate their recruiting brand? How can our theories of trust and credibility be advanced through this recruiting literature? This paper addresses these important questions by investigating the relative importance of information sources and their credibility for judging organizational attractiveness.

The goal of an organizational recruiting system is to affect the number, type, and quality of those applying for and accepting positions with an organization (Breaugh, 1992; Lockwood, 2006). This is of particular importance given the higher skill requirements of international employment (Inkson, Arthur, Pringle, \& Barry, 1997). By attracting and retaining a high quality workforce, organizations can create a competitive advantage in the labor market (Allen, Van Scotter, \& Otondo, 2004; Lado \& Wilson, 1994), and with current and forecasted labor shortages (Jackson \& Schuler, 1990; May, 1998; Rynes, 1991), the task of attracting employees is becoming of greater concern to organizations (Chapman, Uggerslev, Carroll, Piasentin, \& Jones, 2005; Turban \& Greening, 1997). In response to this need, researchers have begun to investigate the characteristics of organizations that make them more attractive to potential employees. Research has found that factors such as pay level and type (Cable \& Judge, 1994), HR systems (Bretz \& Judge, 1994), promotional opportunities (Zedeck, 1977), recruiting processes (Becker, Connolly, \& Slaughter, 2010), and location (Jurgensen, 1978) influence the attractiveness of the organization to potential applicants (Butler, Sanders, Whitecotton, 2000). While this research has contributed to our understanding of how information about the job and organization are related to organizational attractiveness, there remains a significant gap in our understanding.

Potential employees evaluate organizations utilizing a variety of information from a variety of sources including agents of the organization such as recruiters and brochures and "outsiders" such as friends and colleagues (Barber, 1998; pg. 8). Indeed, the number of sources of information has increased significantly with the advent of the internet as a tool for gathering information about organizations (Dineen, Noe, \& Ash, 2002). In addition, researchers have noted that both positive and negative information is available in the labor market (Van Hoye \& Lievens, 2005), which would make it likely that applicants will find a significant amount of conflicting information about organizations. For example, perhaps the organizational recruiter indicated that the organization maintained an employee-friendly culture, while a recent business magazine reported on a sexual-harassment lawsuit. How does the 
applicant reconcile such informational conflicts? It is probable that the applicant would consider the sources of the information and evaluate their respective credibility in order to determine which information would be acted upon. The current study will consider the question of how job seekers use source credibility in selectively utilizing information sources. Specifically, the study addresses three gaps in the recruiting literature.

First, one gap in our understanding of how information about job attributes influences organizational attractiveness deals with a lack of information about the source from which organizational attribute information is received (Van Hoye \& Lievens, 2005). Recent research has illustrated that the behavior of job seekers evaluating organizations is consistent with the elaboration likelihood model (Jones, Shultz, \& Chapman, 2006), suggesting that heuristic cues, such as information source, may have a significant impact on the way in which they process job and organizational information. The majority of research has not been designed to test the influence of information source. For example, a typical study such as Zedeck (1977) that presented information on salary, advancement opportunities, and flexibility to participants does not allow for the influence of information source to be ascertained. Research is therefore needed that creates a more realistic judgment context by making clear the source of the information about the organization.

Second, while it is well known that there are multiple sources of information in the labor market (Gatewood, Gowan, \& Lautenschlager, 1993; Barber, 1998), many past studies have investigated only a limited number of information sources, or a single information source in isolation. Further, by not presenting multiple information sources with conflicting information, much of the ambiguity and uncertainty of the job search process is masked (Rynes, 1991). For example, Schwoerer \& Rosen (1989) manipulated information about employment-at-will-policies in a five-page recruiting brochure. This type of experimental design, where all the information comes from a single source, effectively "holds constant" the source of the information and does not, therefore, allow us to understand how multiple information sources may be used simultaneously. The same is true for other recruiting studies (e.g., Highhouse, Hoffman, Greve, \& Collins, 2002). While some recent research has begun to address this issue (Collins \& Stevens, 2002; Van Hoye \& Lievens, 2005), questions remain regarding why particular sources are used more than others. Research is therefore needed which creates a realistic job choice context involving multiple information sources with conflicting information that must be used simultaneously.

Finally, there has been a call for more research on two different types of information sources. First, the relative importance of institutional information sources, such as the internet (Dineen, et al., 2002), should be considered simultaneously to other sources (Ployhart, 2006). Second, given the proliferation of written media that is being used to transmit recruiting information, researchers have called for more research into recruiting information sent via "intensely personal" information sources (Allen, et al., 2004, pp. 165). The current study investigates a variety of interpersonal and institutional information sources to determine their respective credibility and use in making organizational attractiveness judgments.

\subsection{Information Source and Organizational Attractiveness Judgments}

Rynes (1991) and Barber (1998) call for recruitment research to pay greater attention to recruitment's most immediate objective, applicant attraction. As was stated earlier, several studies have examined the link between job attributes and the attractiveness of the organization (i.e. Harris \& Fink, 1987; Powell, 1984). Although there is no definitive typology (Schwab, Rynes, \& Aldag, 1987), past studies on these attributes has found evidence that compensation levels, promotional opportunities, type of work, and development opportunities are influential in job choice decisions (Zedeck, 1977; Bretz \& Judge, 1994; Jurgensen, 1978). This research was has recently been meta-analyzed by Chapman, et al., (2005) who found that such job attributes as pay, advancement opportunities, organizational environment, and the type of work were strong predictors of organizational attractiveness. The framework used broke the factors affecting organizational attractiveness into the attributes that are specific to the job (Compensation and advancement, pay and benefits, and type of work) and those that are more descriptive of the organization as a whole (Company image, location, and size). The current study draws upon the categories in this meta-analysis as well as more specific studies of the attributes to derive the attributes used to describe the jobs.

Given that attractiveness judgments involve the cognitive processing of information, it may be that factors other than the job-related information may influence ratings of organizational attractiveness. These factors are referred to as peripheral (heuristic) cues in the attitude literature (Eagly \& Chaiken, 1993). The source of the information can serve as such a heuristic cue (Chaiken \& Maheswaran, 1994). Indeed, basic research in attitudes has found strong evidence that the source of a persuasive communication can influence its impact on attitude change (e.g. Petty \& Cacioppo, 1984) and recent recruiting research has begun to consider the importance of such information processing 
models (Jones, Shultz, \& Chapman, 2006). This study investigates how the source from which the information is received may influence how it is used in judging the attractiveness of the organization.

The influence of information source as a heuristics cue is accentuated by the nature of the job choice context. It is also well known that job choice decisions are made with limited and oftentimes uncertain information (Rynes, 1991). That is to say, it is not always clear to job candidates whether or not information about a company is accurate. For instance, information about future promotional opportunities with an organization is inherently uncertain, and impossible to directly verify. It is therefore, impossible for a job candidate to know if the promises of future opportunities are legitimate until sometime after job choice decisions have been made (Caldwell \& O'Reilly, 1985). Thus when individuals make a subjective assessment of the validity of the information, it is likely influenced by the perceived credibility of the source of the information. In other words, whether or not a job candidate believes the information about a particular organization will depend, in part, upon the source of that information.

Multiple Sources. Job search and choice decisions are based on information that is obtained from a variety of information sources (Barber, 1998). This information may come from interpersonal sources (Fisher, Ilgen, \& Hoyer, 1979; Caldwell \& O'Reilly, 1985) including sources affiliated with the organization (e.g., an interviewer or job incumbent) and sources less likely to be affiliated with the organization (e.g., professor, friend, or other professional). In addition, there are also several institutional sources that are used regularly to obtain information about jobs and companies. These institutional sources include recruiting brochures, business magazines, corporate records, and the internet (Capelli, 2001; Betts, 1995; Gatewood et al., 1993).

Thus, individuals rely on information from more than one source when assessing job alternatives (Taylor \& Giannantonio, 1993). In a study of nursing applicants, Williams, Labig, \& Stone (1993) found that $23 \%$ of the new hires had used multiple sources to gather information about the position. Also, Betts (1995) found evidence that students use up to eight different sources to obtain information about salary levels. However, past research on job choice has typically provided participants information from only a single source (i.e. Mason \& Belt, 1986) or has not specified the source of the information at all (i.e. Rynes, Schwab, \& Heneman, 1983; Strand, Levine, \& Montgomery, 1981).

This indicates the need to investigate how these various sources impact information utilization. That is, because multiple information sources exist in the labor market, there is a need to study multiple sources simultaneously. Two recent studies have begun to address this question. In a study of engineering graduates, Collins and Stevens (2002), found that reporting exposure to publicity, advertising, and word-of-mouth endorsements of an organization were positively related to intentions to apply to an organization. A second study by Van Hoye and Lievens (2005) provided participants with negative information about the organization, and then provided positive (conflicting) information from either a recruiting advertisement or word of mouth. They found that receiving positive information did increase organizational attractiveness, but the source of the information did not have a significant influence on the size of that effect. They also found that word of mouth was perceived to be more credible than the recruiting advertisement. These perceptions of credibility, however, did not mediate the relationship between the information from the source and attractiveness.

Given the results of these studies, some important questions remain. Because Collins \& Stevens (2002) did not involve negative information, it does not provide a strong test of the effect of source credibility because sources are not providing conflicting information. Given the negative organizational information available, there remains the question of how job seekers integrate conflicting information. In the Van Hoye and Lievens (2005) study, credibility of the source is assessed, but the measure does not include the subdimensions of credibility and only two information sources are provided. This study will help fill these gaps by providing the realistic context of negative information as well as multiple information sources. In addition, credibility will be operationalized in such a way as to determine the extent to which some sources are perceived as credible for different reasons.

Based on these studies, we can expect that information from each of the multiple sources will be used to judge the attractiveness of the organization, not just information from a single source. For example, in evaluating an organization, the job seeker may consider information from the recruiter, a professor, and a friend, and not rely exclusively on information from one source. Hence the first hypothesis:

H1: Positive information from each of the sources will be related to organizational attractiveness.

Although many information sources are used in job choice decisions (Taylor \& Giannantonio, 1993), it is reasonable to assume that all sources are not used with the same frequency (Betts, 1995). That is to say, it is likely that in making job choice decisions, information from one source would be used more than information from another. We 
would expect that information from particular information sources would have a greater impact on organizational attractiveness than others.

Given that the various information sources would likely provide information that is not entirely consistent, how would a job seeker choose which information to act on? The research on information credibility provides a probable answer to this question.

\subsection{Information Source Credibility}

Given the inherent uncertainty involve in job choice decisions (Rynes, 1991), it is likely that the credibility of the source will influence whether the information is accepted and used in evaluating organizations. Indeed, attitude research suggests that the effect of source credibility is stronger when there is ambiguous information (Chaiken \& Maheswaran, 1994). For our purposes, credibility will be defined as the degree to which a source is seen as providing reliable and accurate information. Researchers have typically broken down credibility into four dimensions: Expertise, Trustworthiness, Integrity, and Likeability. These dimensions have been used in the feedback literature (Ilgen, Fisher, \& Taylor, 1979), the trust literature (Mayer, Davis, \& Schoorman, 1995), and job choice literature (Fisher, et al., 1979) in explaining credibility and similar constructs. Early research on recruitment source and credibility was conducted by Fisher et al. (1979). Using an experimental design, the authors found that the source of the information (recruiter, friend, job incumbent, or professor.) had a significant main effect on source credibility and job offer acceptance. The source seen as most credible was the job incumbent, followed by the friend, and the professor, with the recruiter seen as least credible. There are gaps in this study, however. First, it included only interpersonal information sources (recruiter, professor, etc.), and neglected research suggesting the use of other information sources such as media rankings or internet sites (Betts, 1995; Dineen, et al., 2002). Second, the subjects only received information from a single source, which does not answer the question of how job seekers would integrate conflicting information from multiple sources (Williams, et al., 1993). Each of these gaps will be addressed in the current study.

Information received from sources perceived to be credible is more likely to be seen as valid, and therefore more likely to be used in evaluating the attractiveness of the organization (Van Hoye \& Lievens, 2002). For example, if information about future promotional opportunities is received from a job incumbent (higher credibility) the information would have a greater impact on organizational attractiveness than if it was received from a recruiter (lower credibility). It is hypothesized:

$\mathrm{H} 2$ : Perceived source credibility will be positively related to the extent to which information from a particular source affects organizational attractiveness.

Credibility is typically considered to be multi-dimensional. Because information sources may be perceived as being higher on some dimensions than others, these dimensions will also be considered individually. These dimensions include: Trustworthiness, expertise, integrity, and liking.

Trustworthiness

The trustworthiness dimension of source credibility reflects the motives that the receiver attributes to the source of the information. Research has shown that the motives attributed to a source influence the persuasive ability of its message (Eagly \& Chaiken, 1993) and that information from sources perceived to be untrustworthy is more likely to be critically processed (Priester \& Petty, 1995). It is quite possible that the source could be high in expertise and possess accurate information, but fail to give out that information for ulterior motives. For instance, even though a recruiter could be presumed to have accurate information, he/she also has a reason to distort the information that is provided to the candidate to persuade him/her to accept a position with the company. The more the source is seen as having benevolent motives toward the job candidate, or having the job candidate's best interests in mind, the more the source will be seen as trustworthy. The perceived trustworthiness of the source should be, therefore, related to the credibility of the source and its use in making attractiveness judgments. It follows that:

H3: Perceived source trustworthiness will be positively related to the extent to which information from that source is related to organizational attractiveness.

Expertise

The extent to which a source is seen as credible is related to the perceived expertise of the source. Source expertise has been shown to influence persuasion, particularly in ambiguous judgment contexts (Eagly \& Chaiken, 1993). The expertise of a source of information about an job represents the perceived level of the source's knowledge, competence, or experience that is relevant to the position attributes or organization. A source that is perceived as 
having a high level of expertise is seen as being knowledgeable or possessing accurate information (Fisher et al., 1979). Job candidates are more likely to believe information about a company, and use it in evaluating the company if it comes from a source that is seen as being knowledgeable about the subject.

H4: Perceived source expertise will be positively related to the extent to which information from that source is related to organizational attractiveness.

Integrity

The integrity dimension refers to the consistency shown by the source in adhering to a set of acceptable principles (Mayer et al., 1995). A source that demonstrates integrity adheres to a certain moral principle of what is acceptable, or ethical. Therefore, even if an expert source had negative motives toward an individual, if the source was high in integrity, he/she would still convey accurate information in order to follow those principles. This integrity would allow the job candidate to place more confidence in information provided by the source and act on that information.

H5: Perceived source integrity will be positively related to the extent to which information from that source is related to organizational attractiveness.

Liking

Liking is the fourth hypothesized dimension of credibility. For our purposes, liking can be defined simply as the degree to which an individual has an overall positive evaluation of an object (i.e. person/source). Positive affective reactions have been shown to influence the persuasiveness of influence messages (Eagly \& Chaiken, 1993). Recruiting sources that are associated with such positive affective responses would be more likely to be seen as credible and used in making attractiveness judgments (Fisher et al., 1979). It is hypothesized that:

H6: Liking for a source will be positively related to the extent to which information from that source is related to organizational attractiveness.

\section{Methods and Analysis}

To assess the use of multiple information sources and the influence of information source credibility on organizational attractiveness, a policy capturing approach was utilized. Policy capturing is a statistical procedure that can be used to determine an individual's decision making "policy" or unique method of combining and weighting information (Aiman-Smith, Scullen, \& Barr, 2002). Using policy capturing methodology, instead of asking decision-makers about their priorities, those priorities are statistically estimated based upon the decisions that they make. This is advantageous for this study due to the social desirability that may influence reported job preferences and due to the fact that decision-makers may be unaware of the manner in which source credibility influences their choices. One of the strengths of the policy capturing approach is that it reduces the probability of social desirability bias (Rynes \& Barber, 1990; Arnold \& Feldman, 1981) and only asks decision-makers to provide their actual judgments, not requiring that they have an awareness of how they combined the factors. This method is covered in a review by Karren and Barringer (2002). Policy capturing has been effectively applied to study a variety of human resource management decisions including pay allocation decisions (Beatty, McCune, \& Beatty, 1988), absenteeism (Martocchio \& Judge, 1994), and job choice decisions (Rynes, et al., 1983).

\subsection{Sample}

Because this study was designed to investigate the concept of organizational attractiveness, students who are actively engaged in the job search are an appropriate population from which to sample. The sample consisted of 100 undergraduate students at a large Midwestern university. The majority of the subjects were business majors (90\%) in their junior or senior year. Participants were drawn from two sections of a required human resource management course. Participants ranged in age from 19 to 26, with an average age of 21 and a self reported GPA of 3.1/4.0. The percentage of men (43\%) and women (57\%) was nearly equal.

\subsection{Measures and Procedures}

In order to isolate the effects of information sources, the study used a four by two factorial design in which four sources of information were crossed with two levels of information favorability. By fully crossing these elements, 16 distinct scenarios were created. One practice scenario was also completed by participants but was not included in the analysis. The 17 scenarios were presented to participants in random order. In addition, two versions of the scenarios were used, one using personal sources and one using institutional sources.

Thus, for each scenario, participants received information about the organization from four sources (See Appendix A for sample scenarios). Each of these sources provided either relatively favorable or relatively unfavorable 
information about the organization. While each source described the organization in terms of multiple dimensions (e.g., pay, promotional opportunities, etc.), each company description by a particular source was consistent across dimensions. That is, each source provided a favorable evaluation (e.g., favorable pay, favorable autonomy, favorable opportunities, etc.) or unfavorable evaluation (e.g., unfavorable pay, unfavorable autonomy, unfavorable opportunities, etc.) and in no case did a particular source provide a mixed evaluation across the dimensions. In accordance with the findings of Rynes, et al., (1983), close attention was paid as to making the manipulation approximate realistic labor market levels.

The information provided by sources described the various organizations in terms of pay level, level of autonomy, promotional opportunities, training opportunities, and opportunities to use skills acquired in college. These job-related dimensions have been studied in job choice literature, and found to influence the attractiveness of the positions (i.e. Turban \& Keon, 1993; Rynes et al. 1983; Fisher et al., 1979; Zedeck, 1977).

Finally, participants each received one of two versions of the scenarios. One version of descriptions consisted of information about the company provided by four personal sources: A corporate recruiter, a job incumbent, a professor, and friend. The other version consisted of information provided by four institutional sources: a recruitment brochure, a corporate internet site, a leading business magazine, and the university's placement center. Each participant completed either the interpersonal source or the institutional source version of the questionnaire, with no subjects completing both.

Organizational Attractiveness. Following each scenario, the subjects responded to a number of Likert scale items to assess the organizational attractiveness. A four-item measure adapted from Fisher et al. (1979), was used to assess organizational attractiveness. Example items include: "this company is attractive to me as an employer" and "I would really like to work for this company". The measure showed excellent reliability ( $\alpha=.95)$.

Source Credibility. After completing all 17 scenarios, the participants were asked a series of items to assess the four hypothesized dimensions of credibility (Trustworthiness, integrity, expertise, and likeability) for each of the four sources. While these four dimensions were combined to create a rating of overall credibility, the sub-scales for each dimension were also used in subsequent analyses. Three of the credibility subscales were adapted from Fisher, et al. (1979). Trustworthiness was measured by a three-item measure $(\alpha=.67)$, with sample questions including "I feel this source is extremely trustworthy" and "this source is being honest with me". While this internal consistency is below the conventional level of .70, it is only marginally so, which is more justified in scale development studies such as this (Nunnally \& Bernstein, 1994), and is consistent with the reliability found in Fisher, et al. (1979). Expertise was measured by a three-item scale $(\alpha=.79)$ with sample items being "the source really has expert knowledge about this company" and "this source really has quality information". Liking was measured with a three-item scale $(\alpha=.87)$ with sample items including "I really like this source" and "I enjoy consulting this source for information". The scale for integrity $(\alpha=.71)$ was created based on the conceptual description of integrity given in Mayer et al. (1995) describing integrity as a dimension of interpersonal trust, example items include "this source consistently follows certain principles" and "this source upholds high standards of integrity". All scales were measured on a 5-point likert scale $(1=$ strongly disagree... $5=$ strongly agree). The relative credibility ratings of each source were compared using t-tests. In order to control the familywise error rate for the comparisons, the Bonferroni criterion adjustment was used.

Source Use. Policy-capturing is a methodology for indirectly assessing the policy used by decision-makers by measuring the relationship between the stimuli as predictors of the outcome variable (Aiman-Smith, Scullen, \& Barr, 2002; Karren \& Barringer, 2002). Because all combinations of the four predictor variables were used, we can assume that the variables are orthogonal, eliminating the threat of multicollinearity. In the current study, participants responded sequentially to 17 scenarios. In order to control for within-subject error variance, hierarchical linear modeling (HLM) was used to estimate the weighting given to each of the four sources (Aiman-Smith, Scullen, \& Barr, 2002; Hurt, Mayer, \& Hofmann, 1999). By relating the four predictor variables (positive or negative information from the four sources) to organizational attractiveness, parameter estimates are generated which represent the extent to which the information from each particular source predicts organizational attractiveness. For example, a large parameter estimate for the recruiter would mean that the information given by the recruiter had a large impact on organizational attractiveness. Similarly, a small estimate would mean that information from the recruiter did not impact the participant's judgments. Thus, a set of parameter estimates was calculated separately for each of the 100 participants, with the estimates representing the use of information from each source relative to other sources. In addition, a set of parameter estimates was made for the pooled sample while including gender and age as between-subject control variables. 


\section{Results}

\subsection{Source Use}

Interpersonal Sources. As predicted, for the pooled sample, information from the recruiter $(\beta=.721, p<.001)$, professor $(\beta=.569, \mathrm{p}<.001)$, job incumbent $(\beta=1.01, \mathrm{p}<.001)$, and friend $(\beta=.537, \mathrm{p}<.001)$ all had significant positive effects on the attractiveness of the organization (See Table 1). Thus Hypothesis 1 was supported. The fact that information from all four sources was related to organizational attractiveness supports the contention that multiple sources of information are used in evaluating organizations. While these values are relatively large compared to other policy-capturing job choice studies (e.g., Bretz \& Judge, 1994), the difference must be considered in relation to the number of variables considered. The more important way to interpret the results is in the relative magnitude of the parameter estimates which suggests that information provided by the job incumbent was the best predictor of the attractiveness judgments. Information from the recruiter was used the second most, followed by the professor and friend. Gender was also a significant predictor of organizational attractiveness, with women rating the opportunities as more attractive. While the magnitude of this effect was several times smaller than the source effects, the bivariate analysis (Table 5) indicates that women were significantly more likely to use information from the incumbent $(r=.32, p<.01)$ and less likely to use information from the friend $(r=-.29, p<.01)$. It is also interesting to note that older respondents tended to use information from the recruiter and professor more than the incumbent and friend. Perhaps this would be due to a greater level of experience with such individuals.

\section{Insert Tables 1 about here}

Institutional Sources. Hypothesis 1 was also supported for the institutional sources of information. The placement center $(\beta=.750, \mathrm{p}<.001)$, and business magazine $(\beta=.716, \mathrm{p}<.001)$, were used the most, followed by the internet $(\beta=.566, \mathrm{p}<.001)$, and recruiting brochure $(\beta=.543, \mathrm{p}<.001)$. Interestingly, in the multivariate analysis in the sample rating scenarios with information from institutional sources, gender was not related to attractiveness. However, the bivariate relationship between gender and the use of information from the placement center was significant $(r=.32, p<.01)$ with women being more likely to use that source. Perhaps surprisingly, age showed a nontrivial positive relationship with the use of internet information $(r=.31, \mathrm{~ns})$. Also, age did predict organizational attraction in the multivariate analysis with older participants rating the organizations as less attractive. The magnitude of this effect was also relatively modest. Overall, these results provide support for the use of multiple information sources in recruiting research, as participants used policies that utilized information from all four sources.

\subsection{Source Credibility}

The HLM analysis demonstrated that information from various sources is used to different degrees in evaluating organizations. For example, it is clear that information from the job incumbent was used more often than information from the other sources. In order to investigate the hypothesis that this difference is due to different perceptions of source credibility, a series of paired t-tests was conducted. The mean ratings for each of the credibility dimensions were compared. The means, standard deviations, and correlations among the credibility dimensions are shown in Tables 2 and 3. The general pattern of intercorrelations provides empirical support to the conceptualization that trustworthiness, expertise, integrity, and liking can be viewed as part of the singular construct credibility.

The results of the t-test comparisons are shown in Table 4, and provide clear evidence that the sources are perceived as having different levels of credibility. With one exception, there are statistically significant differences between the mean ratings of at least one source on all four dimensions. Among the interpersonal sources, the friend and job incumbent were seen as most credible, and the recruiter as least credible. With regard to the institutional sources, the placement center and business magazine were rated as the most credible, with the corporate internet site and the recruiting brochure rated as the least credible.

Insert Tables 2-4 about here

Considering the sub dimension of trustworthiness, the friend is significantly more trusted than the job incumbent and recruiter, and the professor and job incumbent also more trusted than the recruiter. A similar pattern is found for institutional sources with the placement center and business magazine being most trusted and the recruiting brochure and internet site being the least trusted.

On the expertise dimension, the job incumbent and the recruiter are seen as most expert among the interpersonal sources. Interestingly, among the institutional sources, there was very little variance in the expertise ratings, with the mean ratings on expertise being statistically indistinguishable. 
With regard to integrity, the friend and the professor, had the highest integrity, the job incumbent was seen as having significantly more integrity than the recruiter. The placement center and magazine were seen as having the most integrity.

On the liking subdimension, the friend was the most liked, with the professor and job incumbent being more liked than the recruiter. The placement center was the most liked of the institutional sources, and the recruiting brochure was the least liked of the sources.

It should be noted that these comparisons come from the participant's direct ratings of the source's credibility. In most cases, these ratings are consistent with the HLM analysis which inferred the sources credibility from the participant's use of information from each source in making their judgments. The exception is the friend, who was rated as having the highest level of credibility but tended to have a lower (although significant) relationship with attractiveness judgments.

\subsection{Source Credibility and Information Use}

Is the variation in participant's policies for using information from the various sources related to their ratings of the sources credibility? One would expect that if a source is used heavily in evaluating the organizations that it would also be rated as a credible source of information. The HLM analysis produced a series of parameter estimates for each subject that represented his/her policy in evaluating the scenarios. The parameter estimates represent the extent to which the information from that source was used in making the organizational attractiveness judgments. The relationship between these parameter estimates and credibility ratings of each source provide an indication of the extent to which variation in source use could be accounted for by source credibility.

To test the hypotheses relating to whether job seeker's use of a particular source is related to the perceived credibility of that source, the zero-order and partial correlations between the weight each subject placed on each source and its respective perceived credibility while controlling for gender and age were calculated. It is important to note that this analysis does not evaluate the use of each source, or the credibility of the source, but rather the extent to which the use of the source was related to its credibility. Due to significant relationships between age, gender, and information source use (Shown in Table 5), the partial correlations are used for the majority of the analyses. Table 6 shows the partial correlations for the interpersonal sources and provides strong support for Hypothesis 2 in that the relationship between the overall credibility and use of the recruiter $(r=.34, p<.01)$, professor $(r=.44, p<.01)$, incumbent $(r$ $=.28, p<.05)$, and friend $(r=.45, p<.001)$ were all statistically significant. Among the institutional sources, the results for overall credibility were more mixed. The relationship between use and overall credibility was statistically significant for the business magazine $(r=.32, p<.01)$, but not for the brochure $(r=.10)$, placement center $(r=.20)$, and internet $(r=.11)$. It should be noted that all the relationships were in the predicted direction and had non-trivial magnitudes. The power to detect the statistically significant effect is attenuated by sample size. In addition, it may be possible that certain dimensions of credibility are more salient for some sources. This possibility can be investigated by considering the partial correlations between source use and each credibility dimension.

\section{Insert Tables 5 and 6 about here}

Among interpersonal and institutional sources, the partial correlation for the trustworthiness dimension was statistically significant for the professor $(r=.30, p<.05)$, incumbent $(r=.30, p<.05)$, and friend $(r=.36, p<.01)$, all of which are interpersonal sources. This suggests that the concept of motives may be more salient to job applicants when evaluating information from people than from institutional sources. Thus hypothesis three received partial support.

The expertise dimension was significantly related to source use for the recruiter $(r=.39, p<.01$, professor $(r=.32, p$ $<.05)$, friend $(r=.39, p<.01)$, and business magazine $(r=.26, p<.05)$. This suggests again that the use of interpersonal sources had a greater tendency to be associated with greater expertise dimensions which was not the case for institutional sources where the integrity dimension appeared more salient. Thus, hypothesis four received partial support.

The integrity dimension was significantly related to source use for six of the eight sources. Both interpersonal sources, including the recruiter $(r=.34, p<.01$, professor $(r=.36, p<.01)$, friend $(r=.29, p<.05)$, and institutional sources, including the brochure $(r=.22, p<.05$, placement center $(r=.38, p<.01)$, and business magazine $(r=.36$, $p<.01)$. This provides support for hypothesis five and suggests that the integrity dimension has the broadest applicability across information sources.

The liking dimension of credibility was positively related to information source use only for the placement center $(r$ $=.24, p<.05)$ and the magazine $(r=.27, p<.05)$, providing only modest support for hypothesis six. It appears that 
affective reactions were most salient to judging organizational attractiveness when evaluating information from institutional sources not associated with the organization.

\section{Contributions and Limitations}

The study has made several practical and theoretical contributions to our understanding of job seeker's use of information in the labor market in assessing the attractiveness of organizations. First of all, the study illustrated how potential applicants use information from multiple sources to evaluate organizations. This was done in a realistic decision making context that included individuals receiving conflicting information from the various sources. The HLM results indicate that information from the job incumbent was used most heavily in evaluating the organization among the interpersonal sources. This finding is consistent with recruiting practices of arranging site visits that allow the recruit to meet with members of the organization. The fact that the job incumbent was used more than the recruiter also suggests that organizations would have greater leverage in influencing organizational attractiveness through the involvement of employees that are not perceived as recruiters.

Many organizations utilize written media for distributing recruiting information. Among the institutional sources, the placement center and the business magazine were most used in forming attractiveness evaluations. This suggests that the efforts organizations make at improving their relationship with third-parties in the recruiting process such as universities and with the popular business press will have a significant influence on job seeker's perceptions of their organization. In addition, because the study design provided participants with scenarios in which sources were providing them conflicting information, the results illustrate that source credibility is one determinant of which source is used in making attractiveness judgments. This is consistent with the findings of Van Hoye and Lievens (2005) in illustrating that negative information in the labor market can be counteracted if the positive information is distributed through more credible sources.

A second contribution of this study is in showing how the differential source use is related to the perceived credibility of the information sources. Overall credibility or one of its subdimensions was a significant predictor of the use of all the sources except for the internet site. This suggests that steps taken to increase the credibility of the source of the recruiting message will increase its influence on perceptions of the organization. In addition, it is interesting to note that the dimensions of credibility that were most strongly related to the use of recruiting information varied by the source. For example, use of information from the recruiters was driven in part by perceptions that they possessed expertise and integrity. Conversely, use of information by the incumbent was driven by perceptions of trustworthiness, ostensibly because the incumbent does not have the same motive to present the organizations favorably as the recruiter. In addition, when the placement center was used as an information source, it was related to overall liking for the source and perceptions of its integrity.

In practice, these links between diverse credibility dimensions and source use suggest two methods for organizations to bolster the effectiveness of their recruiting messages. First, organizations should attempt to send recruiting signals through sources that have the highest level of credibility. Second, organizations can signal the particular credibility dimensions within their recruitment message. For example, a recruiting brochure that signals its legitimacy through the use of signature of leaders, promises, codes of ethics, etc would likely be perceived as having higher integrity and therefore be used more in decisions. Future research can investigate these two methods for creating persuasive messages.

A third contribution of this study is illuminating how job seekers evaluate the credibility of various information sources. While previous studies had investigated the credibility of only a limited number of sources (Van Hoye \& Lievens, 2005) or only interpersonal sources (Fisher, et al., 1979), the current study evaluates a more comprehensive list of potential interpersonal and informational sources. Knowledge that the placement center is perceived as being more credible than a recruiting brochure, for example, has implications for the allocation of recruiting resources. It would suggest that funds and personnel invested in shaping the perceptions and understanding of placement center staff would yield indirect effects on the effectiveness of recruiting programs. This provides empirical support for the recommendations of other researchers (May, 1998). In addition, the high perceived credibility of friends supports the findings of Kilduff (1990) who also found that job preferences parallel the views of peers, and helps partially explain the effectiveness of employee referrals as a source for potential recruits. An endorsement from a friend and a job incumbent would clearly be seen as a credible labor market signal.

Another interesting finding is that while the job incumbent was perceived as having the highest level of expertise, and the next to lowest levels of trustworthiness and integrity, it was the trustworthiness and integrity that were most highly related to using the incumbent as a source. This suggests that if the overall expectations for a source are lower 
there may be a greater opportunity for influence if the organization is able to break out of the stereotype for that source.

Overall, the results indicate that it is important for HR managers responsible for recruiting to systematically determine the sources utilized by potential applicants to obtain information about their company. While not all of these sources are under the organization's control, having delineated these sources, steps can be taken to shape the credibility perceptions of these sources from the applicant's perspective. By signaling the positive information about the organization as well as source credibility, the organization can maximize the effectiveness of its recruiting message. For example, it may be possible to increase the credibility and influence of a recruiting brochure if it includes information from unbiased sources such as business periodicals or company rankings. Future research should investigate the extent to which such cross-signaling influences information source use and organizational attractiveness.

Another interesting area for future research is investigating possible connections between credibility perceptions and individual differences. Although this study has established certain general trends in credibility perceptions, it may be that the individual variance in perceptions is related to performance-relevant individual differences. If future research could establish such connections, it would provide further guidance to HR managers attempting to manage the characteristics of their recruiting pool.

This paper also makes significant theoretical contributions to our understanding of the job choice process. First, the study expands and enriches our models of information use as applicants evaluate jobs. While previous research on factors influencing job choice has assumed that the information is uniformly accepted as credible and accurate, this study furthers our understanding by illustrating that the source from which information is received influences how it is used in decisions. Second, the study expands our understanding of the dimensionality of credibility as it applies to job choice. That is, this study expands the theory of source effects due to credibility by incorporating models of organizational trust with their accompanying dimensions. Finally, the study suggests that theories of choice that presume the rational processing of information can be improved by considering how heuristic processes are used to cope with complex decision-making contexts.

While the study addresses a gap in research on recruiting and organizational attractiveness, it also has some limitations. First, like many recruiting studies, this study relied upon evaluations provided of hypothetical organizations. In addition, the information provided by each source was held constant across scenarios. Neither of these conditions is likely to be the case in real job-choice situations. These constraints were necessary to allow for an experimental design with strong internal validity inferences, but the external validity becomes less certain. It should be noted, however, that consistent with the recommendation of Rynes et al. (1983), the manipulated levels of the variables were realistic for labor market conditions, and multiple information sources were considered which presents a more realistic decision making context. In addition, it was necessary to have each source providing the same types of information in order to avoid confounding the source and information type effects. In any case, future research should investigate these findings in a non-hypothetical research design, as well as consider how information source and type of information might interact. Finally, individual differences relating to credibility judgments (e.g., trust propensity, critical thinking) should also be investigated to determine their relationships with recruiting information sources.

A second limitation is the modest sample size. While policy capturing studies can effectively use small samples due to their within-subject nature (Aimen-Smith, et al., 2002), the between subject analyses may be limited. Future research that utilizes larger samples will increase the generalizability of these results.

Third, the design of the current study does not allow for investigating interactions between the information sign and the information source. Because previous research has suggested that information sources providing counter-motive information are judged to be more credible (Fisher, et al., 1979), it may be that the sign of the information coming from a particular source influences its credibility and use. That is, perhaps positive information from some sources has little effect while negative information from those sources may have a large impact on attractiveness judgments. Because organizations are trying to be credible while simultaneously attracting recruits, better understanding this interaction should be considered in future research.

Fourth, the job seeker's credibility perceptions seemed to drive information source more for interpersonal sources such as recruiters and friends. There are several potential reasons for this finding. First, the dimensions of credibility were derived from literature involving primarily interpersonal sources (e.g., Fisher et al., 1979). In order for applicants to make credibility inferences for institutional sources it requires a certain personification that may not come naturally to decision-makers. Second, due to the personification issue, a greater level of cognitive processing is 
required to critically analyze the motives and integrity of the institutional sources. Such systematic processing is only carried out if there is sufficient motivation and cognitive ability to do so (Chaiken \& Trope, 1999). Finally, people have a tendency to reify written information, assuming that because it is written it must be valid and immutable (Cialdini, 2001). This would likely have the effect of reducing cognitions related to evaluating the credibility of the institutional sources. Future research should consider other dimensions or operationalizations of credibility that may more closely capture the utilization of institutional sources.

In conclusion, this study makes an important contribution to our understanding of recruiting. The influence of information source in a context of conflicting recruiting information had been a gap in our understanding of the recruiting and job choice process. By showing how job seekers react to conflicting recruiting messages differently based on the perceived credibility of multiple interpersonal and institutional information sources, this study helps to fill that gap. Given the proliferation of information sources available in the modern labor market, further research in this area is critical.

\section{References}

Aiman-Smith, L., Scullen, S. E., \& Barr, S. H. (2002). Conducting studies of decision making in organizational contexts: A tutorial for policy-capturing and other regression-based techniques. Organizational Research Methods, 5, 388-414. http://dx.doi.org/10.1177/109442802237117

Allen, D. G., Van Scotter, J. R., \& Otondo, R. F. (2004). Recruitment communication media: Impact on prehire outcomes. Personnel Psychology, 57, 143-171. http://dx.doi.org/10.1111/j.1744-6570.2004.tb02487.x

Arnold, H. J. \& Feldman, D. C. (1981). Social desirability response bias in self-report choice situations. Academy of Management Journal, 24: 249-259. http://dx.doi.org/10.2307/255848

Barber, A. E. (1998). Recruiting employees: Individual and organizational perspectives. Thousand Oaks, CA: Sage.

Barber, A. E., Daly, C. L., Giannantonio, C. M., \& Phillips, J. M. (1994). Job search activities: An examination of changes over time. Personnel Psychology, 47: 739-765. http://dx.doi.org/10.1111/j.1744-6570.1994.tb01574.x

Beatty, J. R., McCune, J. T., \& Beatty, R. W. (1988). A policy-capturing approach to the study of United States and Japanese managers' compensation decisions. Journal of Management, 14: 465-474. http://dx.doi.org/10.1177/014920638801400309

Becker, W.J., Connolly, T., \& Slaughter, J.E. (2010). The effect of job offer timing on offer acceptance, performance, and turnover, Personnel Psychology, 63, 223-241. http://dx.doi.org/10.1111/j.1744-6570.2009.01167.x

Betts, J. R. (1995). What do students know about wages? Evidence from a survey of undergraduates. The Journal of Human Resources, 31: 27-51.

Butler, S.A., Sanders, D.E., \& Whitecotton, S.M. (2000). Student and Recruiter Insights On The Importance of Job Attributes, Journal of Managerial Issues, 12(3) 337-351.

Breaugh, J. A. (1992). Recruitment: Science and Practice Boston: PWS-Kent.

Bretz, R. D. \& Judge, T. A. (1994). The role of human resource systems in job applicant decision processes. Journal of Management, 20: 531-551. http://dx.doi.org/10.1177/014920639402000301

Cable, D. M. \& Judge, T. A. (1994). Pay preferences and job search decisions: A person-organization fit perspective. Personnel Psychology, 47: 317-348. http://dx.doi.org/10.1111/j.1744-6570.1994.tb01727.x

Caldwell, D. F. \& O'Reilly, C. A., III. (1985). The impact of information on job choices and turnover. Academy of Management Journal, 28: 934-943. http://dx.doi.org/10.2307/256246

Capelli, P. (2001). Making the most of on-line recruiting. Harvard Business Review, 79, 139-146.

Chaiken, S. \& Maheswaran, D. (1994). Heuristic processing can bias systematic processing: Effects of source credibility, argument ambiguity, and task importance on attitude judgment. Journal of Personality and Social Psychology, 66: 460-473. http://dx.doi.org/10.1037//0022-3514.66.3.460

Chaiken, S. \& Trope, Y. (1999). Dual-process Theories in Social Psychology. New York: Guilford Press.

Chapman, D. S., Uggerslev, K. L., Carroll, S. A., Piasentin, K. A., Jones, D. A. (2005). Applicant attraction to organizations and job choice: A meta-analytic review of the correlates of recruiting outcomes. Journal of Applied Psychology, 90, 928-944. http://dx.doi.org/10.1037/0021-9010.90.5.928

Cialdini, R. B. (2001). Influence: Science and Practice. Boston: Allyn and Bacon. 
Collins, C. J. \& Stevens, C. K. (2002). The relationship between early recruitment-related activities and the application decisions of new labor-market entrants: A brand equity approach to recruitment. Journal of Applied Psychology, 87, 1121-1133. http://dx.doi.org/10.1037//0021-9010.87.6.1121

Dineen, B. R., Noe, R. A., Ash, S. R. (2002). A web of applicant attraction: Person-organization fit in the context of web-based recruitment. Journal of Applied Psychology, 87, 723-734. http://dx.doi.org/10.1037//0021-9010.87.4.723

Eagly, A. H. \& Chaiken, S. (1993). The Psychology of Attitudes. Harcourt Brace Jovanovich College Publishers, Orlando, FL.

Fisher, C. D., Ilgen, D. R. \& Hoyer, W. D. (1979). Source Credibility, Information Favorability, and Job Offer Acceptance. Academy of Management Journal, 22: 94-103. http://dx.doi.org/10.2307/255481

Gatewood, R. E., Gowan, M. A. and Lautenschlager, G. J. (1993). Corporate image, recruitment image, and initial job choice decisions. Academy of Management Journal, 36: 414-427. http://dx.doi.org/10.2307/256530

Harris, M. M. \& Fink, L. S. (1987). A field study of employment opportunities: Does the recruiter make a difference? Personnel Psychology, 40: 765-784. http://dx.doi.org/10.1111/j.1744-6570.1987.tb00623.x

Highhouse, S., Hoffman, J. R., Greve, E. M., Collins, A. E. (2002). Persuasive impact of organizational value statements in a recruitment context. Journal of Applied Social Psychology, 32, 1737-1755. http://dx.doi.org/10.1111/j.1559-1816.2002.tb02773.x

Hurt, J. L., Maver, J. A., \& Hofmann, D. (1999). Situational and individual influences on judgments of hostile environment sexual harassment. Journal of Applied Social Psychology, 29, 1395-1415. http://dx.doi.org/10.1111/j.1559-1816.1999.tb00145.x

Ilgen, D. R., Fisher, C. D., \& Taylor, M. S. (1979). Consequences of individual feedback on behavior in organizations. Journal of Applied Psychology, 64: 349-371. http://dx.doi.org/10.1037//0021-9010.64.4.349

Inkson, K., Arthur, M. B., Pringle, J., \& Barry, S. (1997). Expatriate assignment versus overseas experience: Contrasting models of international human resource development, Journal of World Business, 32(4) 351-368. http://dx.doi.org/10.1016/S1090-9516(97)90017-1

Jackson, S. E., \& Schuler, R. S. (1990). Human resource planning: Challenges for industrial/organizational psychology. American Psychologist, 45: 223-239. http://dx.doi.org/10.1037//0003-066X.45.2.223

Jones, D. A., Shultz, J. W., \& Chapman, D. S. (2006). Recruiting through job advertisements: The effects of cognitive elaboration on decision making. International Journal of Selection \& Assessment, 14, 167-179. http://dx.doi.org/10.1111/j.1468-2389.2006.00342.x

Jurgensen, C. E. (1978). Job preferences: What makes a job good or bad? Journal of Applied Psychology, 63: 267-276. http://dx.doi.org/10.1037//0021-9010.63.3.267

Karren, R. J. \& Barringer, M. W. (2002). A review and analysis of the policy-capturing methodology in organizational research: Guidelines for research and practice. Organizational Research Methods, 5, 337-361. http://dx.doi.org/10.1177/109442802237115

Kilduff, M. (1990). The interpersonal structure of decision making: A social comparison approach to organizational choice. Organizational Behavior and Human Decision Processes, 47, 270-288. http://dx.doi.org/10.1016/0749-5978(90)90039-C

Lado, A. A., \& Wilson, M. C. (1994). Human resource systems and sustained competitive advantages: A competency-based perspective. Academy of Management Review, 19: 699-727. http://dx.doi.org/10.5465/AMR.1994.9412190216

Lockwood N.R. (2006). Talent management: Driver for organizational success. Alexandria, VA : Society of Human Resources Management.

Martocchio, J. J. \& Judge, T. A. (1994). A policy-capturing approach to individuals' decision to be absent. Organizational Behavior and Human Decision Processes, 57: 358-386. http://dx.doi.org/10.1006/obhd.1994.1020

Mason, N. A. \& Belt, J. A. (1986). Effectiveness of specificity in recruitment advertising. Journal of Management, 12: 425-432. http://dx.doi.org/10.1177/014920638601200311

May, K. (1998). Work in the $21^{\text {st }}$ century: Recruiting in a tight labor market. The Industrial-Organizational Psychologist (TIP), 36, 39-41. 
Mayer, R. C., Davis, J. H., \& Schoorman, F. D. (1995). An integrated model of organizational trust. Academy of Management Review, 20: 709-734. http://dx.doi.org/10.5465/AMR.1995.9508080335

Nunnally, J. C., \& Berstein, I. H. (1994). Psychometric Theory ( ${ }^{\text {rd }}$ ed.). New York: McGraw-Hill.

Petty, R. E., \& Cacioppo, J. T. (1984). Source factors and the elaboration likelihood model of persuasion. Advances in Consumer Research, 11: 668-672.

Ployhart, R. E. (2006). Staffing in the $21^{\text {st }}$ century: New challenges and strategic opportunities. Journal of Management, 32, 868-897. http://dx.doi.org/10.1177/0149206306293625

Powell, G. N. (1984). Effects of job attributes and recruiting practices on applicant decisions: A comparison. Personnel Psychology, 37: 721-732. http://dx.doi.org/10.1111/j.1744-6570.1984.tb00536.x

Priester, J. R. \& Petty, R. E. (1995). Source attributions and persuasion: Perceived honesty as a determinant of message scrutiny. Personality and Social Psychology Bulletin, 21, 637-654. http://dx.doi.org/10.1177/0146167295216010

Rynes, S. A. (1991). Recruitment, job choice, and post-hire consequences: A call for new research directions. In Dunnette, M. D. and Hough, L. M. (Eds.) Handbook of Industrial and Organizational Psychology, (2 ${ }^{\text {nd }}$ ed.) 2: 339-444. Palo Alto: Consulting Psychologists' Press.

Rynes, S. A., \& Barber, A. E. (1990). Applicant attraction strategies: An organizational perspective. Academy of Management Review, 15: 286-310. http://dx.doi.org/10.2307/258158

Rynes, S. A., Bretz, R. D., \& Gerhart, B. (1991). The importance of recruitment in job choice: A different way of looking. Personnel Psychology, 44: 487-521. http://dx.doi.org/10.1111/j.1744-6570.1991.tb02402.x

Rynes, S. L., Schwab, D. P., \& Heneman, H. G. (1983). The role of pay and market pay variability in job application decisions. Organizational Behavior and Human Performance, 31: 353-364. http://dx.doi.org/10.1016/0030-5073(83)90130-7

Schwab, D. P., Rynes, S. L., \& Aldag, R. J. (1987). Theories and research on job search and choice. In K. Rowland $\&$ G. Ferris (Eds.), Research in personnel and human resources management, 5, 129-166. Greenwich, CT: JAI Press.

Schwoerer, C. \& Rosen, B. (1989). Effects of employment-at-will policies and compensation policies on corporate image and job pursuit intentions. Journal of Applied Psychology, 74: 653-656. http://dx.doi.org/10.1037//0021-9010.74.4.653

Strand, R., Levine, R., \& Montgomery, D. (1981). Organizational entry preferences based upon social and personnel policies: An information integration perspective. Organizational Behavior and Human Performance, 27: 50-68. http://dx.doi.org/10.1016/0030-5073(81)90038-6

Taylor, M. S. \& Giannantonio, C. M. (1993). Forming, adapting, and terminating the employment relationship: A review of the literature from individual, organizational, \& interactionist perspectives. Journal of Management, 19: 461-515. http://dx.doi.org/10.1016/0149-2063(93)90060-Z

Turban, D. B. \& Greening, D. W. (1997). Corporate social performance and organizational attractiveness to prospective employees. Academy of Management Journal, 40: 658-672. http://dx.doi.org/10.2307/257057

Turban, D.B. \& Keon, T.L. (1993). Organizational attractiveness: An interactionist perspective. Journal of Applied Psychology, 78: 184-193. http://dx.doi.org/10.1037//0021-9010.78.2.184

Van Hoye, G. \& Lievens, F. (2005). Recruitment-related Information Sources and Organizational Attractiveness: Can Something Be Done About Negative Publicity? International Journal of Selection and Assessment, 13, 179-187. http://dx.doi.org/10.1111/j.1468-2389.2005.00313.x

Williams, C. R., Labig, C. E., \& Stone, T. H. (1993). Recruitment sources and posthire outcomes for job applicants and new hires: a test of two hypotheses. Journal of Applied Psychology, 78: 163-172. http://dx.doi.org/10.1037//0021-9010.78.2.163

Zedeck, S. (1977). An information processing model and approach to the study of motivation, Organization Behavior and Human Performance, 18: 47-77. http://dx.doi.org/10.1016/0030-5073(77)90018-6 
Table 1. Policy Capturing Hierarchical Linear Model Parameter Estimates of Information Source Use

\begin{tabular}{cc}
\hline & Parameter \\
Variable & Estimate \\
\hline
\end{tabular}

Interpersonal Sources

Main Effects

Control Variables

Recruiter

Professor

Job Incumbent

Friend

Age

Gender
$.721^{* * *}$

$.569^{* * *}$

$1.01 * * *$

$.537^{* * *}$

$-.021$

$.091^{*}$

\section{Institutional Sources}

$\begin{array}{cll}\text { Main Effects } & & \\ & \text { Recruiting Brochure } & .543^{* * *} \\ & \text { Placement Center } & .750^{* * *} \\ & \text { Internet } & .566^{* * *} \\ & \text { Business Magazine } & .716^{* * *} \\ \text { Control Variables } & & \\ & \text { Age } & -.049^{* *} \\ & \text { Gender } & -.090\end{array}$

Note: For interpersonal sources, $n=47$, for institutional sources, $n=53$

$* \mathrm{p}<.05 * * \mathrm{p}<.01 * * * \mathrm{p}<.001$

Table 2. Correlations between Perceptions of Interpersonal Source Credibility Dimensions

\begin{tabular}{|c|c|c|c|c|c|c|c|c|c|c|c|c|c|c|c|c|c|c|c|c|c|}
\hline Variable & $M$ & $S D$ & 1 & 2 & 3 & 4 & 5 & 6 & 7 & 8 & 9 & 10 & 11 & 12 & 13 & 14 & 15 & 16 & 17 & 18 & 19 \\
\hline 1. Recruiter & 3.05 & .51 & & & & & & & & & & & & & & & & & & & \\
\hline 2. Trustworthiness & 2.84 & .72 & & & & & & & & & & & & & & & & & & & \\
\hline 3. Expertise & 3.43 & .68 & & $.52 * * *$ & & & & & & & & & & & & & & & & & \\
\hline 4. Integrity & 2.84 & .59 & & $.68 * * *$ & $.53 * * *$ & & & & & & & & & & & & & & & & \\
\hline 5. Liking & 3.07 & .54 & & $.52 * * *$ & $.44 * *$ & $49 * * *$ & & & & & & & & & & & & & & & \\
\hline 6. Professor & 3.52 & .35 & .07 & & & & & & & & & & & & & & & & & & \\
\hline 7. Trustworthiness & 3.75 & .47 & & .03 & -.14 & -.03 & -.02 & & & & & & & & & & & & & & \\
\hline 8. Expertise & 2.95 & .72 & & $.37 * *$ & $.35 * *$ & 18 & .28 & & .13 & & & & & & & & & & & & \\
\hline 9. Integrity & 3.82 & .47 & & -.21 & .10 & -.08 & -.08 & & $.35^{*}$ & .12 & & & & & & & & & & & \\
\hline 10. Liking & 3.55 & .51 & & $-.29 *$ & -.09 & -.24 & -.04 & & .18 & .08 & $.57 * * *$ & & & & & & & & & & \\
\hline 11. Incumbent & 3.58 & .41 & .04 & & & & & .03 & & & & & & & & & & & & & \\
\hline 12. Trustworthiness & 3.53 & .60 & & .15 & -.09 & .17 & .00 & & -.04 & -.26 & -.21 & .05 & & & & & & & & & \\
\hline 13. Expertise & 3.95 & .53 & & -.03 & .01 & -.13 & .09 & & -.03 & .04 & .12 & $.34 *$ & & $.42 * *$ & & & & & & & \\
\hline 14. Integrity & 3.43 & .52 & & .14 & -.01 & .27 & .02 & & -.28 & -.26 & .02 & .18 & & $.58^{* * *}$ & $.31 *$ & & & & & & \\
\hline 15. Liking & 3.39 & .51 & & -.02 & .00 & -.09 & .06 & & .00 & .00 & $.32 *$ & $.54 * * *$ & & $.33^{*}$ & $.50 * * *$ & $.44 * *$ & & & & & \\
\hline 16. Friend & 3.68 & .39 & $.29 *$ & & & & & $.34 *$ & & & & & -.18 & & & & & & & & \\
\hline 17. Trustworthiness & 3.89 & .54 & & .14 & .19 & .17 & -.20 & & $.38^{* *}$ & .07 & .02 & -.24 & & -.03 & -.13 & -.14 & $-.32 *$ & & & & \\
\hline 18. Expertise & 2.75 & .71 & & $.31 *$ & $.35^{*}$ & $.34 *$ & .20 & & -.17 & $.51^{* * *}$ & -.12 & -.13 & & -.22 & -.16 & -.08 & -.19 & & .11 & & \\
\hline 19. Integrity & 3.87 & .48 & & .07 & .15 & -.04 & -.16 & & .26 & .17 & $.49 * * *$ & .28 & & -.21 & .03 & -.05 & .15 & & $.38 * *$ & $.31^{*}$ & \\
\hline 20. Liking & 4.21 & .58 & & .24 & $.35^{*}$ & .09 & -.06 & & $.34 *$ & .18 & $.35 * *$ & .08 & & -.09 & .05 & -.14 & .09 & & $.50 * * *$ & .05 & $.58 * * *$ \\
\hline
\end{tabular}


Table 3. Correlations between Perceptions of Institutional Source Credibility Dimensions

\begin{tabular}{|c|c|c|c|c|c|c|c|c|c|c|c|c|c|c|c|c|c|c|c|c|c|}
\hline Variable & $M$ & $S D$ & 1 & 2 & 3 & 4 & 5 & 6 & 7 & 8 & 9 & 10 & 11 & 12 & 13 & 14 & 15 & 16 & 17 & 18 & 19 \\
\hline 1. Recruiting Brochure & 3.04 & .65 & & & & & & & & & & & & & & & & & & & \\
\hline 2. Trustworthiness & 2.90 & .77 & & & & & & & & & & & & & & & & & & & \\
\hline 3. Expertise & 3.26 & .62 & & $.68^{* * *}$ & & & & & & & & & & & & & & & & & \\
\hline 4. Integrity & 3.10 & 67 & & $.62^{* * *}$ & $50^{* * * *}$ & & & & & & & & & & & & & & & & \\
\hline 5. Liking & 2.91 & .93 & & $.75^{* * *}$ & $68 * * *$ & $73 * * *$ & & & & & & & & & & & & & & & \\
\hline 6. Placement Center & 3.67 & .53 & -.02 & & & & & & & & & & & & & & & & & & \\
\hline 7. Trustworthiness & 3.76 & .54 & & .09 & .19 & -.07 & -.02 & & & & & & & & & & & & & & \\
\hline 8. Expertise & 3.42 & .72 & & .24 & .10 & .13 & .11 & & $.54 * * *$ & & & & & & & & & & & & \\
\hline 9. Integrity & 3.79 & .56 & & -.09 & .04 & -.03 & -.13 & & $.52^{* * *}$ & $59 * * *$ & & & & & & & & & & & \\
\hline 10. Liking & 3.72 & .76 & & -.10 & -.11 & -.24 & -.19 & & $.57^{* * *}$ & $52 * * *$. & $.59 * * *$ & & & & & & & & & & \\
\hline 11. Internet & 3.23 & 61 & .10 & & & & & -.23 & & & & & & & & & & & & & \\
\hline 12. Trustworthiness & 3.09 & .74 & & $.32 *$ & .10 & .07 & .15 & & -.10 & -.06 & -.13 & -.17 & & & & & & & & & \\
\hline 13. Expertise & 3.36 & .72 & & -.03 & .01 & -.06 & -.09 & & -.01 & -.07 & -.15 & -.13 & & $.70^{* * *}$ & & & & & & & \\
\hline 14. Integrity & 3.13 & 63 & & .25 & .17 & .10 & .10 & & -.17 & -.13 & -.17 & -.22 & & $67^{* * *}$ & $67 * * *$ & & & & & & \\
\hline 15. Liking & 3.32 & .72 & & .02 & -.10 & .09 & .08 & & -.13 & -.25 & $-.34 * *$ & $-.31 *$ & & $64 * * *$. & $75^{* * *}$ & $59 * * *$ & & & & & \\
\hline 16. Magazine & 3.59 & .60 & -.07 & & & & & .04 & & & & & .00 & & & & & & & & \\
\hline 17. Trustworthiness & 3.59 & 60 & & .20 & -.07 & -.04 & -.06 & & .17 & -.09 & -.19 & -.11 & & .10 & .06 & .09 & .17 & & & & \\
\hline 18. Expertise & 3.56 & .71 & & .06 & .03 & -.01 & -.16 & & .23 & .17 & .10 & -.12 & & -.02 & .11 & -.03 & .01 & & $.54 * * *$ & & \\
\hline 19. Integrity & 3.58 & .70 & & .02 & -.01 & -.09 & -.15 & & .20 & -.09 & .04 & -.04 & & -.09 & -.04 & -.06 & -.05 & & $.68^{* * *}$ & $75^{* * *}$ & \\
\hline 20. Liking & 3.65 & .71 & & -.04 & -.12 & -.13 & -.21 & & .22 & -.01 & .03 & .04 & & -.08 & .04 & -.11 & .00 & & $.65^{* * *}$ & $72 * * *$ & **** \\
\hline
\end{tabular}

Table 4. Information Source Credibility Mean Ratings t-tests

\begin{tabular}{|c|c|c|c|c|}
\hline & $\begin{array}{c}\text { Interpersonal } \\
\text { Sources }\end{array}$ & & $\begin{array}{c}\text { Institutional } \\
\text { Sources }\end{array}$ & \\
\hline Overall Credibility & $\begin{array}{l}\text { Friend } \\
\text { Job Incumbent } \\
\text { Professor } \\
\text { Recruiter }\end{array}$ & $\begin{array}{l}3.68 \\
3.58 \\
3.52 \\
3.05\end{array}$ & $\begin{array}{l}\text { Placement Center } \\
\text { Business Magazine } \\
\text { Internet Site } \\
\text { Recruiting Brochure }\end{array}$ & $\begin{array}{l}3.67 \\
3.59 \\
3.23 \\
3.04\end{array}$ \\
\hline Trustworthiness & $\begin{array}{l}\text { Friend } \\
\text { Professor } \\
\text { Job Incumbent } \\
\text { Recruiter }\end{array}$ & $\begin{array}{l}3.89 \\
3.75 \\
3.53 \\
2.84\end{array}$ & $\begin{array}{l}\text { Placement Center } \\
\text { Business Magazine } \\
\text { Internet Site } \\
\text { Recruiting Brochure }\end{array}$ & $\begin{array}{l}3.76 \\
3.59 \\
3.09 \\
2.90\end{array}$ \\
\hline Expertise & $\begin{array}{l}\text { Job Incumbent } \\
\text { Recruiter } \\
\text { Professor } \\
\text { Friend }\end{array}$ & $\begin{array}{l}3.95 \\
3.43 \\
2.95 \\
2.75\end{array}$ & $\begin{array}{l}\text { Business Magazine } \\
\text { Placement Center } \\
\text { Internet Site } \\
\text { Recruiting Brochure }\end{array}$ & $\begin{array}{l}3.56 \\
3.42 \\
3.36 \\
3.26\end{array}$ \\
\hline Integrity & $\begin{array}{l}\text { Friend } \\
\text { Professor } \\
\text { Job Incumbent } \\
\text { Recruiter }\end{array}$ & $\begin{array}{l}3.87 \\
3.82 \\
3.43 \\
2.84\end{array}$ & $\begin{array}{l}\text { Placement Center } \\
\text { Business Magazine } \\
\text { Internet Site } \\
\text { Recruiting Brochure }\end{array}$ & $\begin{array}{l}3.79 \\
3.58 \\
3.13 \\
3.10\end{array}$ \\
\hline Liking & $\begin{array}{l}\text { Friend } \\
\text { Professor } \\
\text { Job Incumbent } \\
\text { Recruiter }\end{array}$ & $\begin{array}{l}4.21 \\
3.55 \\
3.39 \\
3.07\end{array}$ & $\begin{array}{l}\text { Placement Center } \\
\text { Business Magazine } \\
\text { Internet Site } \\
\text { Recruiting Brochure }\end{array}$ & $\begin{array}{l}3.72 \\
3.65 \\
3.32 \\
2.91\end{array}$ \\
\hline
\end{tabular}

Note: Means are statistically different unless connected by a bar. For interpersonal sources, $n=47$, for institutional sources, $n=53$. The Bonferroni criterion adjustment was used to correct the family-wise error rate. 
Table 5. Zero-Order Correlations between Information Source Use, Overall Perceived Source Credibility, and Control Variables

\section{Recruiter Professor Incumbent Friend Brochure Placement Internet Magazine}

\begin{tabular}{lcccccccc}
\hline Overall Credibility & $\mathbf{. 3 5 * *}$ & $\mathbf{. 4 4 * *}$ & $\mathbf{. 3 6 *}$ & $\mathbf{. 5 0 * * *}$ & $\mathbf{. 0 8}$ & $\mathbf{. 1 8}$ & $\mathbf{. 0 3}$ & $\mathbf{. 2 9 *}$ \\
Age & .22 & .20 & -.06 & -.09 & .10 & -.05 & .31 & .05 \\
Gender & -.04 & -.14 & $.32 *$ & $-.29 *$ & .04 & $.32 *$ & .09 & .10 \\
& & & & & & & \\
&
\end{tabular}

Table 6. Partial Correlations between Information Source Use and Perceived Source Credibility Controlling for Age and Gender

\section{Recruiter Professor Incumbent Friend Brochure Placement Internet Magazine}

\begin{tabular}{lllllllll} 
Overall Credibility & $\mathbf{. 3 4 * *}$ & $\mathbf{. 4 4 * *}$ & $\mathbf{. 2 8 *}$ & $\mathbf{. 4 5 * * *}$ & $\mathbf{. 1 0}$ & $\mathbf{. 2 0}$ & $\mathbf{. 1 1}$ & $\mathbf{. 3 2 * *}$ \\
Trustworthiness & .20 & $.30^{*}$ & $.30^{*}$ & $.36^{* *}$ & .12 & -.01 & .21 & .19 \\
Expertise & $.39 * *$ & $.32^{*}$ & .11 & $.39 * *$ & -.09 & .08 & .01 & $.26^{*}$ \\
Integrity & $.34^{* *}$ & $.36^{* *}$ & .23 & $.29 *$ & $.22^{*}$ & $.38^{* *}$ & .14 & $.36^{* *}$ \\
Liking & .15 & .18 & .17 & .18 & .03 & $.24 *$ & -.07 & $.27^{*}$ \\
& & & & & & & & \\
\hline
\end{tabular}

Note: For interpersonal sources, $n=47$, for institutional sources, $n=53 .{ }^{*} \mathrm{p}<.05 * * \mathrm{p}<.01{ }^{* * *} \mathrm{p}<.001$ 


\section{Appendix A}

Sample Scenario: Interpersonal Sources

Assume that you are currently on the job market, looking for a full time position. You wanted to get information about the job and the company from several sources. You received information from a recruiter from the organization, your major professor, a job incumbent on a plant tour, and your best friend who is also interviewing with the organization.

The recruiter said that the training and promotional opportunities are outstanding, with opportunities to use the skills you gained in college immediately in an entry-level position. Pay is quite good, paying about $5 \%$ above the industry average. And, although there are some routine things to do, the position generally allows you $a$ lot of autonomy in working independently on several interesting projects.

The professor said that training and promotional opportunities are quite good, with opportunities to use the skills you gained in college after proving yourself in an entry-level position. The pay is not bad, typically paying about 5\% below the industry average. And, although much of what you do is somewhat routine, the position occasionally allows you some freedom to work on an interesting project.

The job incumbent said training and promotional opportunities are outstanding, with opportunities to use the skills you gained in college immediately in an entry-level position. Pay is quite good, paying about $5 \%$ above the industry average. And, although there are some routine things to do, the position generally allows you $\underline{a}$ lot of autonomy in working independently on several interesting projects.

Your friend who also is considering the company said training and promotional opportunities are quite good, with opportunities to use the skills you gained in college after proving yourself in an entry-level position. The pay is not bad, typically paying about $5 \%$ below the industry average. And, although much of what you do is somewhat routine, the position occasionally allows you some freedom to work on an interesting project.

Based on this information, please indicate the extent to which you agree with the following statements.

I am very interested in pursuing a position with this company.

Strongly Disagree Disagree Uncertain Agree Strongly Agree

$\begin{array}{lllll}1 & 2 & 3 & 4 & 5\end{array}$

I would be very willing to accept a job with this company if offered one.

Strongly Disagree Disagree Uncertain Agree Strongly Agree

$\begin{array}{lllll}1 & 2 & 3 & 4 & 5\end{array}$

I would really like to work for this company.

Strongly Disagree Disagree Uncertain Agree Strongly Agree

$\begin{array}{lllll}1 & 2 & 3 & 4 & 5\end{array}$

This company is attractive to me as an employer.

Strongly Disagree Disagree Uncertain Agree Strongly Agree

$\begin{array}{lllll}1 & 2 & 3 & 4 & 5\end{array}$


Sample Scenario: Institutional Sources

Assume that you are currently on the job market, looking for a full time position. You wanted to get information about the job and the company from several sources. You received information from a recruitment brochure, an independent Internet site, a leading business magazine, and from files kept at the university's placement office.

The recruitment brochure said that the training and promotional opportunities are outstanding, with opportunities to use the skills you gained in college immediately in an entry-level position. Pay is quite good, paying about $5 \%$ above the industry average. And, although there are some routine things to do, the position generally allows you a lot of autonomy in working independently on several interesting projects.

The corporate internet site said that training and promotional opportunities are quite good, with opportunities to use the skills you gained in college after proving yourself in an entry-level position. The pay is not bad, typically paying about $5 \%$ below the industry average. And, although much of what you do is somewhat routine, the position occasionally allows you some freedom to work on an interesting project.

The leading business magazine said training and promotional opportunities are outstanding, with opportunities to use the skills you gained in college immediately in an entry-level position. Pay is quite good, paying about $5 \%$ above the industry average. And, although there are some routine things to do, the position generally allows you a lot of autonomy in working independently on several interesting projects.

The university's placement center information said training and promotional opportunities are quite good, with opportunities to use the skills you gained in college after proving yourself in an entry-level position. The pay is not bad, typically paying about $5 \% \underline{\text { below }}$ the industry average. And, although much of what you do is somewhat routine, the position occasionally allows you some freedom to work on an interesting project.

Based on this information, please indicate the extent to which you agree with the following statements.

I am very interested in pursuing a position with this company.

Strongly Disagree Disagree Uncertain Agree Strongly Agree

$\begin{array}{lllll}1 & 2 & 3 & 4 & 5\end{array}$

I would be very willing to accept a job with this company if offered one.

Strongly Disagree Disagree Uncertain Agree Strongly Agree

$\begin{array}{lllll}1 & 2 & 3 & 4 & 5\end{array}$

I would really like to work for this company.

Strongly Disagree Disagree Uncertain Agree Strongly Agree

$\begin{array}{lllll}1 & 2 & 3 & 4 & 5\end{array}$

This company is attractive to me as an employer.

Strongly Disagree Disagree Uncertain Agree Strongly Agree

$\begin{array}{lllll}1 & 2 & 3 & 4 & 5\end{array}$

